\title{
Sorption of Ethane and Propane by 2nd-Stage Cesium-Graphite Intercalation Compound
}

\author{
Kazuko Oi, Takayuki Terai and Yoichi Takahashi
}

(Received August 16, 1990)

Department of Nuclear Engineering, University of Tokyo, 7-3-1 Hongo, Bunkyo-ku, Tokyo 113, Japan

Sorption behavior of aliphatic hydrocarbons such as ethane and propane by the 2nd-stage cesium-graphite intercalation compound $\left(\mathrm{CsC}_{24}\right)$ was examined. Both ethane and propane were found to be sorbed at the low temperatures $(194-287 \mathrm{~K})$ up to the compositions of $\mathrm{CsC}_{24}\left(\mathrm{C}_{2} \mathrm{H}_{6}\right)_{0.9}$ and $\mathrm{CsC}_{24}\left(\mathrm{C}_{3} \mathrm{H}_{8}\right)_{0.7}$, respectively.

The sorption-desorption characteristics were reproducible and the saturation compositions were enhanced with decreasing temperatures, indicating these phenomena to be physisorption.

KEYWORDS: Cesium-graphite intercalation compound, Ethane, Propane, Physisorption

\section{INTRODUCTION}

The second-stage alkali-metal intercalation compounds(AM-GICs) are known to have fairy. large spaces between the intercalated atoms and a variety of gases such as $\mathrm{H}_{2}, \mathrm{~N}_{2}$, etc. are known to be physi-intercalated in the spaces at low temperatures. A few studies have been done, however, on the sorption of aliphatic hydrocarbons: Watanabe et al. reported the sorption of $\mathrm{CH}_{4}$ by $\mathrm{RbC}_{24}$ and $\mathrm{CsC}_{24}$ at $161 \mathrm{~K}^{1)}$. Goldman et al. have recently found that $n$-hexane is sorbed by $\mathrm{CsC}_{24}$ around room temperature ${ }^{2)}$.

We report here, as a short communication, that aliphatic hydrocarbons such as ethane and propane are also sorbed by $\mathrm{CsC}_{24}$ at low temperatures.

\section{EXPERIMENTAL}

About $2 \mathrm{~g}$ of the second-stage $\mathrm{CsC}_{24}$ was prepared from natural graphite (flakes of $10 \mu \mathrm{m}$ on average) and metallic cesium in two steps. First, the 1st-stage $\mathrm{CsC}_{\mathbf{8}}$ was synthesized using "two-bulb method". The $\mathrm{CsC}_{8}$ compound was then well annealed with the stoichiometric amount of graphite to convert it into $\mathrm{CsC}_{24}$. The chemical compositions of the 2nd-stage $\mathrm{CsC}_{24}$ samples thus prepared were confirmed by the measurement of the sample masses. Hydrocarbon gases used had the purity higher than $99.8 \%$ and were used as purchased.

The $\mathrm{CsC}_{24}$ sample preapred was transferred to a glass vessel under inert atmosphere. The vessel was then attached to a vacuum system for sorption experiments. The sample was kept at certain temperatures using a cooling bath. The temperature of the sample was monitored by a thermocouple attached to the outer surface of the sample container. All the system was evacuated under $10^{-3} \mathrm{~Pa}$ and then known amount of hydrocarbon gases were stepwisely introduced. After the attainment of equilibrium, the volume of the gas sorbed by the $\mathrm{CsC}_{24}$ sample was determined from the change of pressure upon sorption according to the "constant volume method". Helium gas was used for the dead volume measurement. When the desorption curve was measured, the system was evacuated stepwisely to lower pressures at 


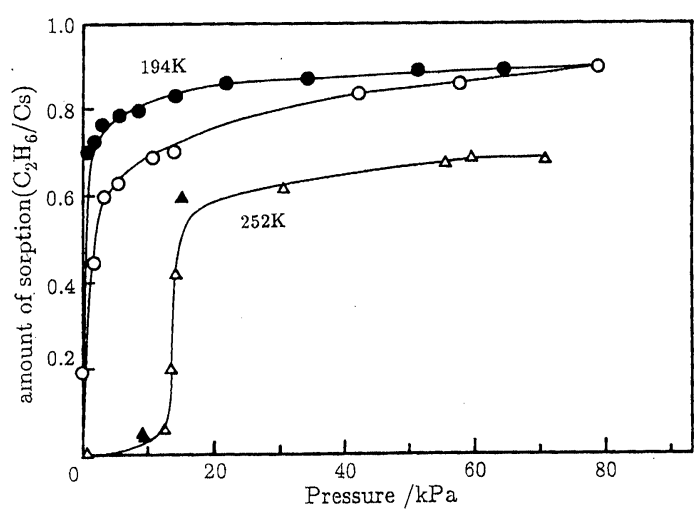

Fig. 1 Sorption-desorption curves for the system $\mathrm{CsC}_{24}-\mathrm{C}_{2} \mathrm{H}_{6}$ at $194 \mathrm{~K}$ and $252 \mathrm{~K}$ : $\mathrm{\triangle}$, sorption; $\bullet \mathbf{\Lambda}$, desorption.

the same low temperature. Finally, in order to complete the desorption, the system was evacuated at room temperature.

In order to examine the degradation of the $\mathrm{CsC}_{24}$ which may be caused during these sorption-desorption operations, the sorptive capacity of the sample against hydrogen gas was checked before and after each sorptiondesorption cycle.

\section{RESULTS AND DISCUSSION}

Both ethane and propane were found to be sorbed by $\mathrm{CsC}_{24}$ up to the compositions of $\mathrm{CsC}_{24}\left(\mathrm{C}_{2} \mathrm{H}_{6}\right)_{0.9}$ at $194 \mathrm{~K}$ and $\mathrm{CsC}_{24}\left(\mathrm{C}_{3} \mathrm{H}_{8}\right)_{0.7}$ at $252 \mathrm{~K}$, respectively. The sorption and desorption equilibriums were almost attained in several hours. In most cases, isotherms of sorption and desorption were identical. An exception was for the isotherm of ethane at $194 \mathrm{~K}$, which showed an apparent hysterisis (Figs. 1 and 2). The sorption behavior for all the samples was reproducible by the evacuation at room temperature, and the sorptive capacity of the samples against hydrogen gas showed no difference before and after the sorption-desorption cycle, indicating the intactness of the samples during the operation. Thus the sorption-desorption processes were confirmed to be reversible.

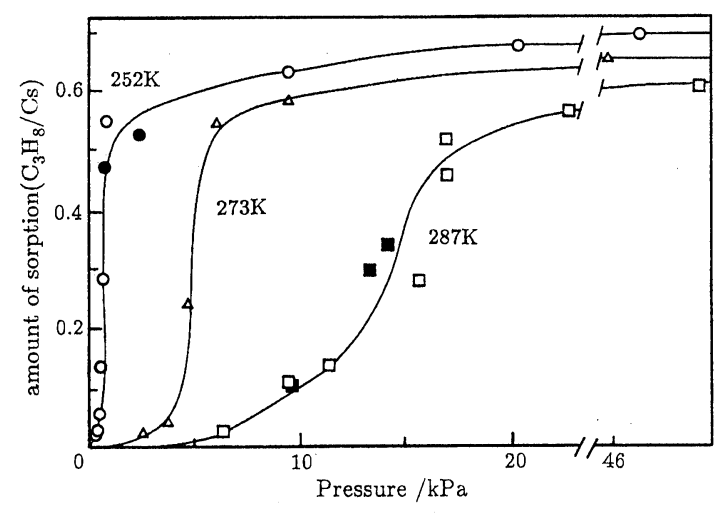

Fig. 2 Sorption-desorption curves for the system $\mathrm{CsC}_{24}-\mathrm{C}_{\mathbf{3}} \mathrm{H}_{\mathbf{8}}$ at $252 \mathrm{~K}, 273 \mathrm{~K}$ and 287K: $\bigcirc \triangle \square$, sorption; $\square$, desorption.

As shown in Figs. 1 and 2, the amount of sorption apparently increased with decreasing temperature. In the case of propane, a small amount of sorption (approximately $\mathrm{CsC}_{24}$ $\left.\left(\mathrm{C}_{3} \mathrm{H}_{8}\right)_{0.07}\right)$ was also observed even at a high temperature of $313 \mathrm{~K}$. The reversibility and the enhancement of sorption at low temperatures thus indicate that these sorption-desorption phenomena are physisorption.

The saturation compositions of the sorption of ethane and propane, $\mathrm{CsC}_{24}\left(\mathrm{C}_{2} \mathrm{H}_{6}\right)_{0.9}$ and $\mathrm{CsC}_{24}\left(\mathrm{C}_{3} \mathrm{H}_{8}\right)_{0.7}$, can be compared with the cases of methane $\left(\mathrm{CsC}_{24}\left(\mathrm{CH}_{4}\right)_{1.2}\right)^{1)}$ and $\mathrm{n}$ hexane $\left(\mathrm{CsC}_{24}\left(\mathrm{C}_{6} \mathrm{H}_{14}\right)_{0.44}\right)^{2)}$. We can see a tendency that the amount of hydrocarbon sorbed by $\mathrm{CsC}_{24}$ becomes smaller with increasing the molecular size of the gases.

Further studies on the properties of series of aliphatic hydrocarbons- $\mathrm{CsC}_{24}$ systems are under way.

\section{References}

1) K. Watanabe, T. Kondow, M. Soma, T. Onishi \& K. Tamaru, Proc. R. Soc. (London) Ser. A 333, 51 (1973)

2) M. Goldman, H. Pilliere \& F. Beguin, Synth. Met. 34, 59 (1989) 